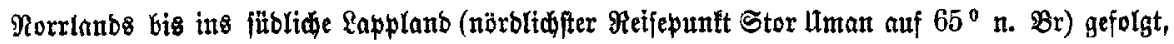
bie now ïber 100 Teilnebymer batte.

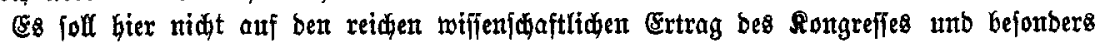

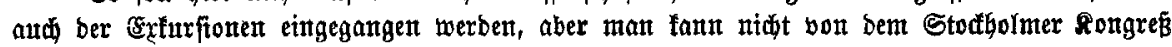
reben, ohne mit wärmftem Danf feiner Beranftalter unb aller berer z̆ gebenfen, bie groß̈e Opfer bradten, um bie Sadje bez Rongreffes żu förbern unb ben fremben Gäften auts ber

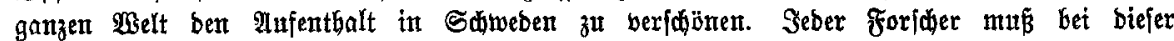
(Selegenbeit empfunben baben, wie wertboll für iłan bas perjönlide Betanntwerben mit Fads= genoffen anberer \&änber unb bic Bereifung frember $\mathfrak{M}_{\text {albgebiete }}$ unter funtbiger $F$

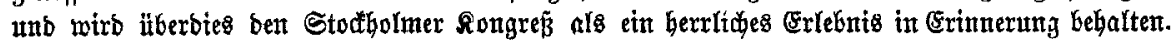

$\mathfrak{F a b r i c i u s . ~}$

\title{
Eberswalder Fodifinulwodhe.
}

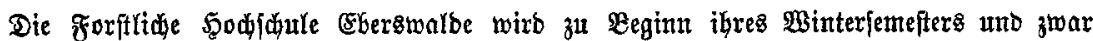

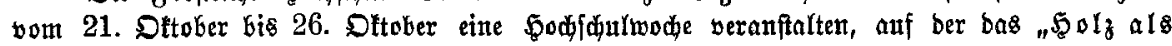
Frobaft ber Forftwirtfdaft" in ben Mittelpuntt afler Borträge unt Refreusflitge geftellt

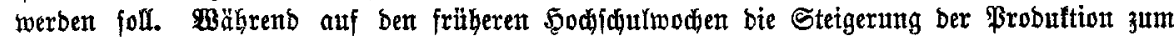

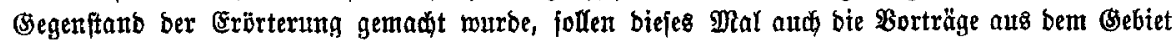

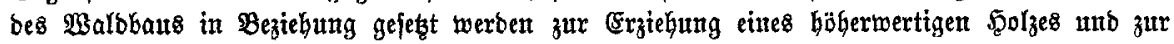

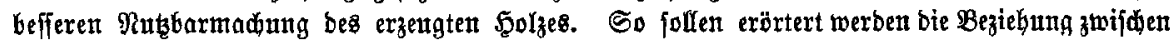

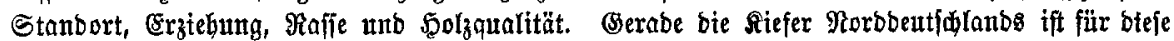
Frngen ein Gervorragenbes Beifpiel. Bei biefer (Belegenheit werben insbejonbere aud biejentgen

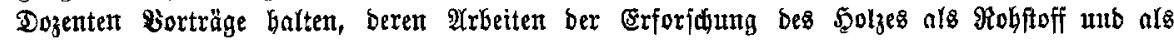

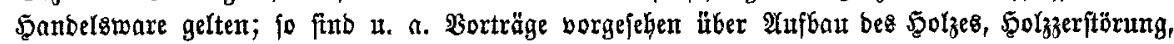

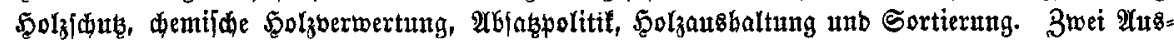

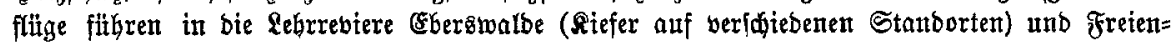

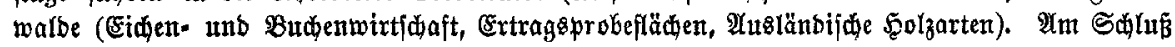

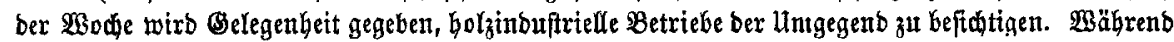

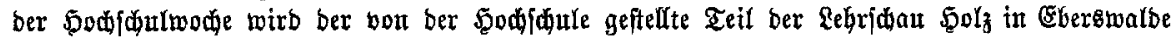

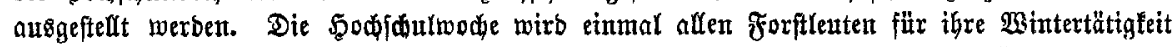

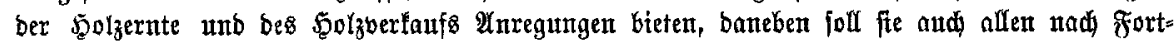

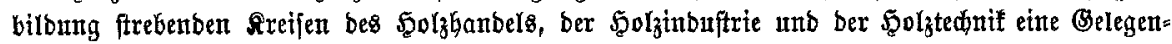

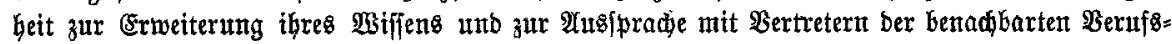

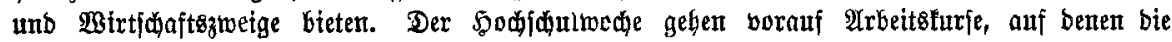
Rattonalifierung ber Balbarbeit behanbelt mirb. Ein genaues \$rogramm ber Sodjidultwode

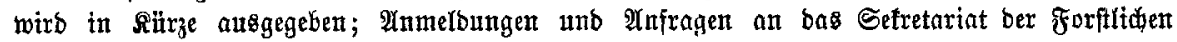
Sedoffdule finb zeitig ermïnidgt.

\section{forftlithe Arbeitswiffenfinaft.}

Das Snfititut fitr forfflide Arbettswiffenfodaft wirb in ber Beit voln 10.-19. Dltober

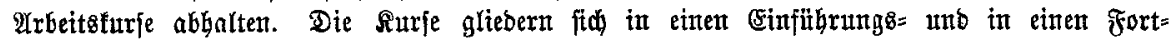
bilbung : Rehrgang.

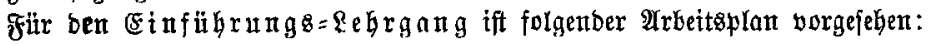

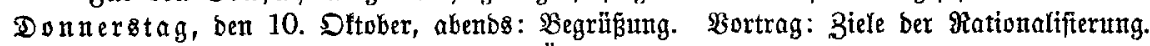
Freitag, ben 11. Oftober vormittags: Übungen im Walbe. Zeiffubien im Saunngsketrieb. nadimittags: 2Hasmertung ber Beitftubien.

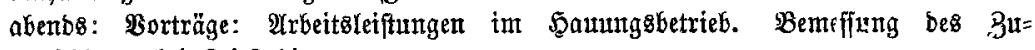
fallages bet Beitfitubten. 